\title{
An Inventory Model for Perishable Items Having Constant Demand with Time Dependent Holding Cost
}

\author{
Sarbjit Singh \\ Institute of Management Technology, India
}

Copyright $(2016$ by authors, all rights reserved. Authors agree that this article remains permanently open access under the terms of the Creative Commons Attribution License 4.0 International License

\begin{abstract}
This paper presents an inventory model for perishable items with constant demand, for which holding cost increases with time, the items considered in the model are deteriorating items with a constant rate of deterioration $\theta$. In the majority of the earlier studies the holding cost has been considered to be constant, which is not true in most of the practical situations as the insurance cost and record keeping costs or even cost of keeping the items in the cold storage increases with time. In this paper the time dependent linear holding cost has been considered, the holding cost for the items increases with time. The approximate optimal solution has been obtained. The results are illustrated with the help of numerical examples.
\end{abstract}

Keywords Cycle Period, Deterioration, EOQ, Ordering Cost, Holding Cost

\section{Introduction}

Inventory is a part and parcel of each and every organization, whether it is manufacturing or service organization. All organizations have to keep some inventory for smooth running of their business. If any organization claims that they are not keeping any inventory it's an absurd.

The Economic Order quantity model is one of the oldest known models developed by [15] and a lot of work has been done on this model. In the last few decades the study of perishable items has gained enormous importance. In present scenario the wastage of resources is considered as a sin. Even most of the companies are facing cut throat competition and deterioration of resources would reduce their profit margins drastically. Therefore, in most of the present models the items considered are deteriorating items and inventory cost compromises of the deterioration cost.

Ghare and Schrader were the pioneer to use the concept of deterioration, they developed an inventory model with a constant rate of deterioration [5], followed by [4] who formulated a model considering a variable rate of deterioration with two parameter Weibull distribution, which was further extended by [12]. Nahmais [11] provided the relevant literature on the problem of determining suitable ordering policies for both fixed life perishable inventory, and inventory subject to continuous exponential decay.

Cheng worked on an economic order quantity model with demand-dependent unit production costs and solved the problem using geometric programming to obtain the optimal cost [3]. One of the major issues related to have the balance of stock dependent demand and deteriorating items, therefore the inventory model for deteriorating items having stock dependent demand was formulated [13]. Then the models for other species of the demands had been formulated and solved, the two models for deteriorating items with linearly time dependent demand where replenishment rate changes linearly with the change in demand and on-hand inventory amount was formulated and validated [1]. The same year the study focused on an extended EOQ-type deterministic inventory models for a perishable product where demand rate is a function of the on-hand inventory was done. In this study the holding cost is treated as a nonlinear function of the length of time for which the item is held in stock was considered [6].

Taking the study of deteriorating items further the production model of deteriorating items was obtained, which provided an optimal production stopping and restarting times for an EOQ model with deteriorating items [7].

The study of the perishable items got strengthened by [3] when it had been proved that the inventory carrying cost is in the proportion to the cost of deteriorated items, and then offered a formulated approximated solution. Taking the study to further heights an inventory model for deteriorating items with stock dependent demand and time varying demand for finite planning horizon was proposed [16] and then Economic Production Quantity model for perishable items having stock dependent demand was formulated which brought the concept of deteriorating items in the production model species of the inventory management [14].

Considering the other important factors of inventory management like Inflation time value of money Kuo-Lung Hou [8] developed an inventory model for deteriorating items with stock-dependent consumption rate and shortages 
under inflation and time discounting. Incorporating the permissible delay in payments the model for the optimal retailers' replenishment decisions having deteriorating items under two levels of trade credit policy to reflect supply chain management within the economic production quantity (EPQ) framework was developed [9].

In this paper an attempt has been made to frame an inventory policy for perishable items like food items, fashion goods, etc. with constant demand and time dependent holding cost. Earlier Muhlemann \& Spanopoulos[10] revised the classical EOQ model with time dependent holding cost and permissible delay in payments. In classical EOQ model only two costs, i.e. ordering and carrying cost have been considered and the optimal solution is the point where the ordering cost is equal to the carrying cost. Here in this study the model has been developed in which third cost i.e deteriorating cost has been considered, also the carrying cost considered is not constant, it increases with time. This study provides the mechanism by which the retailers can decide about their cycle period and economic order quantity, for the items whose holding cost increases with time. Thus, keeping the stock of items for a long time will increase the cost drastically which has been shown in the numerical illustrations. Here, it is assumed that the holding of items increases linearly with time. The sensitivity of the decision variable has been done and optimal solution has obtained for the case given in numerical illustrations.

\section{Notations and Assumptions}

The following notations are used in developing the model.

$\mathrm{D}_{\mathrm{T}} \quad$ Amount of material deterioration during a cycle time, $\mathrm{T}$

$\theta$ Deterioration rate, a fraction of the on-hand inventory

c The unit cost per item (dollars/unit)

$\mathrm{S} \quad$ The ordering cost of inventory (dollars/order)

D The demand rate (units per unit time)

$\mathrm{T}$ Replenishment cycle time

$C_{H} \quad$ The total cost of holding inventory per cycle

$C_{D} \quad$ Total deterioration cost per cycle

Q The Economic Order quantity (EOQ) ordered at the time $\mathrm{t}=0$

$\mathrm{h}+\lambda \mathrm{t} \quad$ The time dependent holding cost

$\mathrm{I}(\mathrm{t}) \quad$ The inventory level at time $\mathrm{t}$

Assumptions

I adopt the following assumptions and notations for the model to be discussed.

1) The demand for items is constant for the planning horizon.

2) The item cost remains constant irrespective of the order size.

3) Shortages are not allowed.

4) Replenishment rate is infinite and the lead time is zero.

5) The replenishments are instantaneous.

6) The holding constant increases with time.

7) The items considered are perishable items

8) The deterioration rate is constant; a constant fraction $\theta(0 \leq \theta \leq 1)$ of inventory deteriorates per unit time.

9) There is no repair or replenishment of the deteriorated items during the inventory cycle.

10) $\mathrm{L}$ is the length of the finite planning horizon.

11) The inventory is replenished only once in each cycle.

\section{Mathematical Model and Analysis}

In this model deterministic demand is considered with a constant rate of deterioration, depletion of the inventory occurs due to demand (supply) as well as due to deterioration in each cycle. The instantaneous states of $I(t)$ over the cycle time $\mathrm{T}$ is given by the following first order nonlinear differential equation.

$$
\frac{d I(t)}{d t}+\vartheta I(t)=-D, 0 \leq t \leq T
$$

Solving equation (1), we obtain I ( $\mathrm{t}$ ) during the time period $(0 \leq t \leq T)$ a

$$
I(t)=-\frac{D}{\vartheta}+C e^{-\theta t}, 0 \leq t \leq T
$$

Where $\mathrm{C}$ is constant of integration

Using the condition, that at the completion of cycle time i.e., at the time $t=T, \mathrm{I}(\mathrm{T})=0$, we obtain

$$
I(t)=\frac{D}{\theta}\left(e^{\theta(T-t)}-1\right) 0 \leq t \leq T
$$

At time $\mathrm{t}=0, \mathrm{I}(\mathrm{T})=\mathrm{Q}$ i.e. when the items are received, the level at which the organization is having a maximum inventory and equation (3) give the economic order quantity (EOQ) i.e. the quantity ordered at the start of the cycle. As it is assumed there is no lead time, i.e. items are received instantaneously. Hence order is placed when the inventory level reaches zero.

$$
Q^{*}=\frac{D}{\theta}\left(e^{\theta T}-1\right)
$$

Since the total demand during cycle period T is DT, the amount of materials which deteriorates during one cycle is

$$
D_{T}+Q-D T=\frac{D}{\vartheta}\left(e^{\theta T}-1\right)-D T
$$

The total variable cost will consist of the following costs

a) The ordering cost of the materials, which is fixed at $\mathrm{S}$ dollars/order for the present financial year.

b) The deterioration cost is given by $c D_{T}$ which comes out to be 


$$
C_{D}=c\left[\frac{D}{\vartheta}\left(e^{\theta T}-1\right)-D T\right]
$$

c) The holding cost is the function of average inventory cost and it is given by

$$
C_{H}=\int_{0}^{T} I(t)(h+\lambda t) d t
$$

Which, upon simplification, yields

$C_{H}=\frac{D}{\theta^{3}}\left((h \theta+\lambda) e^{\vartheta T}-\vartheta T\left(\lambda+\vartheta h-\frac{\lambda T}{2}\right)-\vartheta h-\lambda\right)$

Total variable cost function for one cycle is given by

$$
\begin{gathered}
T V C=S+C_{D}+C_{H} \\
T V C=S+\frac{c D}{\theta}\left(e^{\theta T}-1-\theta T\right)+ \\
\frac{D}{\theta^{3}}\left((h \theta+\lambda) e^{\vartheta T}-\vartheta T\left(\lambda+\vartheta h-\frac{\lambda T}{2}\right)-\vartheta h-\lambda\right)
\end{gathered}
$$

The Total Variable Cost per unit time, TC, is simply given by

$$
\begin{aligned}
& T C=\frac{S}{T}+\frac{c D}{\theta T}\left(e^{\theta T}-1-\theta T\right)+ \\
& \frac{D}{\theta^{3} T}\left((h \theta+\lambda) e^{\vartheta T}-\vartheta T\left(\lambda+\vartheta h-\frac{\lambda T}{2}\right)-\vartheta h-\lambda\right)
\end{aligned}
$$

The total cost obtained is convex, hence provide the optimal solution. Using the principle of maxima and minima the optimal cycle time and the economic order quantity can be obtained.

\section{Numerical Illustrations}

Considering a retailer whose yearly demand is 1000 units and the unit price of each unit is $\$ 100$. The ordering $\operatorname{cost}(\mathrm{S})$ is $\$ 1000$, constant rate of deterioration $\theta$ is $5 \%$ and $\mathrm{h}=\$ 5$ and $\lambda=3$, using the equation 9 with different cycle times the total cost has been obtained given in the table 1 below.
The optimal cycle comes out to be 0.05 years, the number of cycles in a year $=20$ and total inventory cost is $\$ 41215.4$. The graph of the cost is given in Appendix 1. This proves that in the case of the time dependent holding cost it is optimal to have a shorter cycle time unless the ordering cost is very high. Thus, the number of cycles per year is large.

Table 1. Optimal cycle time for the model

\begin{tabular}{|c|c|}
\hline Cycle Time (Years) & Total Cost(\$) \\
\hline 0.3 & 130871 \\
\hline 0.2 & 90016.71 \\
\hline 0.1 & 52504.17 \\
\hline 0.06 & 42168.17 \\
\hline 0.05 & 41251.04 \\
\hline 0.04 & 42000.67 \\
\hline
\end{tabular}

\section{Conclusions}

In this paper, the model formulated for the perishable items provides retailers a mechanism to decide their economic order quantity and the cycle time for the items having variable holding cost. This model provides a simple framework for retailers to decide about the optimal inventory levels without doing any mathematical modeling. The holding cost plays the most crucial role in the total inventory cost and plays an important role in deciding the optimal order quantity. In most of the earlier studies, it has been assumed that holding cost is constant irrespective of the cycle time, which is absurd in most of the cases.

In this model the holding cost considered increases linearly with time. Thus, unless ordering cost is very high, in most of the cases the optimal economic order quantity is small with large number of cycles, which has proved by the numerical illustrations. In this study lead time is considered to negligible but this model can also be used for the situation when lead time is constant and accordingly the orders can be placed. The proposed model can be extended in several ways. For instance, shortages can be allowed, permissible delay in payments, inflation, time value for money can be incorporated. This model can further be extended for items having stock dependent demand. 


\section{Appendix 1}

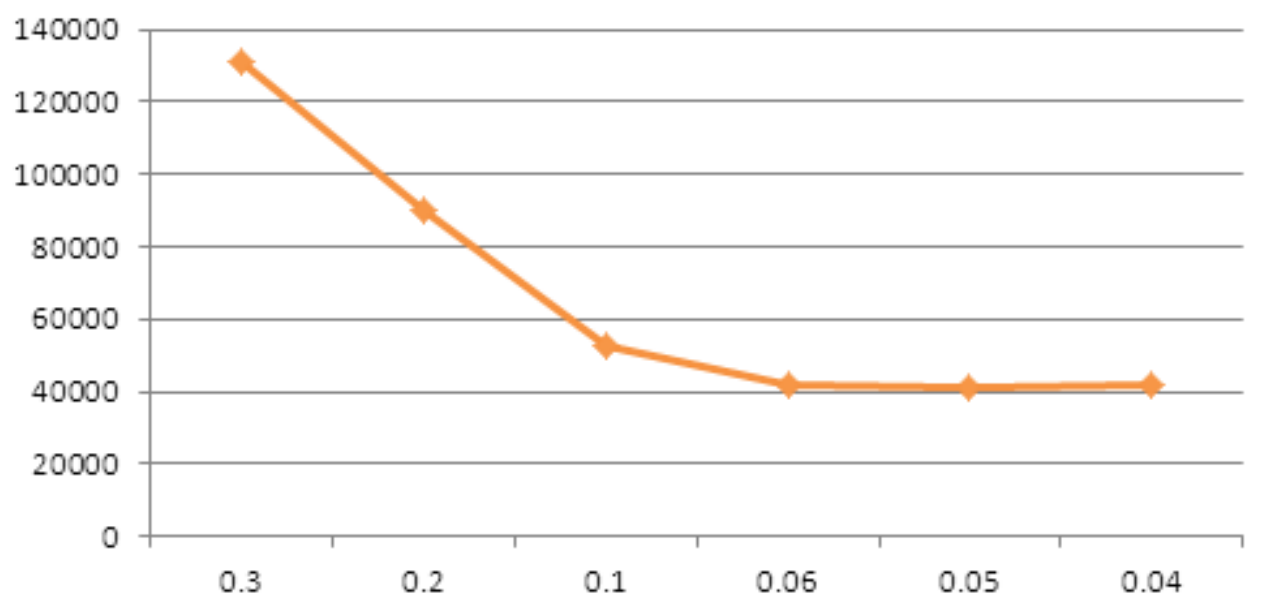

\section{REFERENCES}

[1] Bhunia A.K and M. Maiti, 1998. Deterministic inventory model for deteriorating items with finite rate of replenishment dependent on inventory level. Computers and Operations Research 25 (11), 997-1006.

[2] Cheng TCE., 1991. An economic order quantity model with demand-dependent unit production cost and imperfect production processes, IIE Transactions 23, 23-28.

[3] Chu. P and Patrick S.H., 2002. A note on inventory replenishment policies for deteriorating items in an exponentially declining market. Computers and Operations Research 29 (13), 1827-1842.

[4] Covert, R.P and G. C. Philip, 1973. An EOQ model for items with Weibull distributed deterioration. AIIE Transactions 5, 323-326

[5] Ghare and Schrader. 1963. A model for exponential decaying inventory. Journal of Industrial Engineering 14(3), 238-43.

[6] Giri , B.C and Chaudhari K.S. .1998. Deterministic models of perishable inventory with stock dependent demand rate and nonlinear holding cost 105, 467-474.

[7] H Yan and TCE Cheng, 1998. Optimal production stopping and restarting times for an EOQ model with deteriorating items. Journal of Operational Research Society 49, 1288-1295.

[8] Kuo-Lung Hou, 2006. An inventory model for deteriorating items with stock-dependent consumption rate and shortages under inflation and time discounting. European Journal of Operations Research 168,463-474.

[9] Mahatma Gour Chandra, 2012. An EPQ inventory model for exponentially deteriorating items under retail partial trade policy in supply chain, Expert Systems and applications.39(3), $3537-3550$

[10] Muhlemann, A.P. and Spanopoulos Valtis., 1980. A variable holding cost rate EOQ model, European Journal of operational Research 4, 132-135.

[11] Nahmias S., 1982. Perishable inventory theory a review. Operations Research 30, 680-708

[12] Pal, S., Goswami, A., and Chaudhari, K.S., 1993. A deterministic inventory model for deteriorating items with stock dependent demand rate, International Journal of Production Economics. 32, 291-299.

[13] Shah Y.K and Jaiswal, M.C., 1977. An order level lot size inventory for deteriorating items AIIE Transactions 9(2), 108-12.

[14] Teng J.T. and Chang C.T., 2005. Economic production quantity models for deteriorating items with price- and stock-dependent demand. Computers and Operations Research 32, 297-308.

[15] Wilson R.H., 1934. A scientific routine for stock control. Harvard Business Review, 13, 116-128.

[16] Zaid T. Balkhi \& Lakdere Benkherouf., 2004. On an inventory model for deteriorating items with stock dependent demand and time-varying demand rates. Computers and pertains Research 31, 223-240. 